\title{
The use of real options approach in energy sector investments
}

\author{
Bartolomeu Fernandes , Jorge Cunha, Paula Ferreira \\ Department of Production and Systems, University of Minho, Campus de Azurém, 4800-058 Guimarães, Portugal
}

\begin{abstract}
a b s tract
Energy shortage, global warming, and climate change led to an increase in the use of alternative sources of energy, with renewable energy sources (RES) playing a fundamental role in this new energetic paradigm. However, the investment costs often constitute a major barrier to their spread use. Moreover, the overall benefits of renewable energy technologies are often not well understood and consequently they are often evaluated to be not as cost effective as traditional technologies. From the moment that the energy sector started a deregulation process, with a high level of competitiveness and associated increased market uncertainty, traditional project evaluation techniques alone became insufficient to properly deal with these additional risk and uncertainty factors. The diffusion of the renewable energy technologies is also affected by this feature. The way investors evaluate their investments call now for the use of more sophisticated evaluation techniques. Real options approach can deal with these issues and, as so, began to be considered and applied for the energy sector decision aid. This approach it is now extensively widespread in evaluating investment projects in the energy sector. A large set of applications in almost all fields of energy decision making, from electricity generation technologies appraisal to policy evaluation is available in the literature. However the use of this technique in the field of RES is still limited and worth to be analysed. This paper addresses this issue. A review of the current state of the art in the application of real options approach to investments in non-renewable energy sources and RES is presented, giving perspectives for further research in this field.
\end{abstract}

1. Introduction

2. Basic principles of real options theory

2.1. Financial call options

2.2. Real options definition

2.3.Common types of real options

3. Valuing real options

4. Application of the real options theory to the energy sector

4.1.Application of the real options theory to renewable energy sources investment projects

4.1.1. Real options theory in power generation investment

4.1.2. Real options theory in policy evaluation

5. Conclusion

4.1.3. Real options theory in R\&D investments/programs

Acknowledgments

References

\section{Introduction}

The use of renewable energy sources (RES) emerges as a necessary condition to achieve sustainable development. Energy

E-mail addresses: bartolomeuafernandes@gmail.com (B. Fernandes), jscunha@dps.uminho.pt (J. Cunha), paulaf@dps.uminho.pt (P. Ferreira). shortage, global warming, and climate change forced an increase in the use of alternative sources of energy. Nay, the world's economy is affected by the prices of the raw materials and is in turn affected by the constant instability of the fuel-based energy prices. For these reasons, RES have a fundamental role in providing universal access to energy, creating new business opportunities, reducing the external energy dependency and, at the same time, contributing to reduction of greenhouse gas emis-sions.

However, RES are not competitive when compared to other generation technologies. Partly, because of the fact of the invest-ment costs often constitute a major barrier to their spread use [1]. Moreover, the overall benefits of renewable energy technologies are often not well understood and consequently they are often evaluated to be not as cost effective as traditional technologies. Consequently, in order to RES become competitive the ensuring of adequate support schemes is necessary encouraging investments in this field [2].

However, a good support scheme may not be enough to encourage investments. The increase of the generation capacity in a liberalized market, requires taking into account future uncertain-ties [3]. Traditional evaluation models relying mainly on discounted cash-flows 
fail to assess the strategic dimension of the investments and do not allow for properly dealing with the risk and uncertainty of these particular projects. The diffusion of the renewable energy technologies is also affected by this feature, so, the way investors evaluate their investments call for the use of more sophisticated evaluation techniques. Real options theory, gives the investor the ability to account for the value inherent in the flexibility to delay an irreversible investment into the future. In the RES projects field, this ability become particularly important, as these are often modu-lar, normally require short construction times and exhibit learning curves with very steep slopes $[4,5]$.

The remainder of this paper is organized as follows. Section 2 gives an introduction of the basic principles of the real options the-ory. Section 3 presents a line of thought to real options valuing model. Section 4, firstly, provides a literature review on the applica-tion of the real options theory to non-renewable energy projects, to understand the importance and the applicability of this technique. Secondly, a literature review of the application of this technique to RES projects is presented. Section 5 concludes the paper presenting the main findings and some perspectives for further research.

\section{Basic principles of real options theory}

Wrong investment decisions today can lead to situations in the future that will be unsustainable and lead eventually to the bankruptcy of enterprises. Therefore, good financial management combined with good capital investment decision-making are criti-cal to survival and long-term success of the firms [6].

Traditionally, the net present value (NPV) and discounted cash flow (DCF) methods are worldwide used to evaluate project investments $[7,8]$. However given that, today investments are char-acterized by high risks and uncertainty, DCF methodologies are inadequate to deal with these issues. These traditional techniques make implicit assumptions, like the reversibility of investments, in other words, an investment can be undone and the expenditures recovered. On the other hand, if a firm do not undertake the invest-ment now, it will not be able to do it in the future and this will become unrecoverable [9].

Although, there are some investment projects that have these features, most of them do not have it. In fact, the ability to delay an investment, in order to obtain more information and thus reducing uncertainty, provides management with a valuable opportunity to modify both investment and the strategy to follow, in order to get better future opportunities or to reduce future losses.

Thereby, this possibility can be seen as an option due to the fact that a company has the opportunity to invest, or simply not investing, similar to a financial call option [9].

From this premise, the capital budgeting can be treated in the field of real options. This term that was firstly used by Myers [10]. Additionally, Trigeorgis [11] stated that "an options approach to capital budgeting has the potential to conceptualize, and even quantify, the value of options from active management. This value is manifest as a collection of corporate real options embedded in capital investments opportunities. ..."

Unlike traditional methods, the real options theory centres on the valuation of the managerial flexibility to answer to different scenarios with high levels of uncertainty. This theory is known as a modern approach for economic valuation of projects under uncertainty [12].

The concept of real options arises from financial options. Its foundations lay in the Nobel Prize awarded work on the pricing of financial option contracts, developed by Black, Merton and Scholes. The option-pricing theory had applications for all kind of invest-ments, whether they are real or nonfinancial [13]. Thus, the real options theory is a natural extension of the option-pricing theory.

To a better understanding of the real options theory, it is important to introduce the concept of financial call options and afterwards the definition of real options.

\subsection{Financial call options}

According to Black and Scholes [13], "An option is a security giving the right to buy or sell an asset, subject to certain condi-tions, within a specified period of time". Options represent rights, therefore the yield of an option can never be less than zero, inde-pendently of the underlying asset.

There are two types of basic options, the ones that give the right to buy (call) an asset at a pre-specified price (exercise price) in specified period (time to maturity) and those that give the right to sell (put) an asset in exchange for receiving an exercise price in a pre-specified time (time to maturity). When the option exercise price is below the current price of the underlying asset (for a call option), or above the current price of the underlying asset (for a put option), it is said that the option is "in the money". Otherwise, it is "out of the money".

Options can be either European or American. When the option can be exercised only on a specified future date that option is des-ignated of "European option". On the other hand, when the option can be exercised at any time up to the date the option expires that option is designated of "American option".

\subsection{Real options definition}

There are some definitions of real options, however all of them tend refer to the same concepts. Thus, two definitions are presented as follows.

Copeland and Antikarov [14] defined real option "as the right, but not the obligation, to take an action (e.g., deferring, expanding, contracting or abandoning) at a predetermined cost, called exercise price, for a predetermined period of time - the life of the option".

Another definition was given by Kogut and Kulatilaka [15], where real options were defined as "an investment decision that is characterized by uncertainty, the provision of future managerial discretion to exercise at the appropriate time, and irreversibility".

So, an opportunity to invest is similar to a call option. If a firm with an opportunity to invest has the option to spend money (exer-cise price) now or in the future, in return for an asset (e.g., project) of some value, would invest, if the option is "in the money", and receive a positive net payoff. Otherwise, the firm would not invest if the option is "out of the money", to avoid a negative net payoff. Table 1 shows this analogy.

\subsection{Common types of real options}

In this subsection a summary of the most common real options will be presented. Although there are several types of real options, Trigeorgis [11] argues that the most common are the defer, time-tobuild, alter operating scale, abandon, switch and growth options. 
Table 1

Analogy of the call option and the project characteristics.

\begin{tabular}{ll}
\hline Project characteristics & Call option \\
\hline Present value of expected cash flows & Stock price \\
Present value of investment outlays & Exercise price \\
Length of deferral time & Time to maturity \\
Time value of money & Risk-free rate \\
Volatility of project's returns & Variance of stock returns \\
\hline
\end{tabular}

The defer option gives the holder the ability to wait to invest the money. This means that, one with an investment opportunity has the option to spend the money now, or wait for more information about the investment or simply wait for the resolution of the uncer-tainty [9]. These options are frequently applied on investments in industries of natural resource extraction, real-estate development, farming and many other projects that can be deferred [11].

Many investment projects have some particular characteristics, such as requiring a construction and or start-up time that does not allow to return any profit until it is completed or involving some decisions and cash expenses that may occur sequentially over time. Real options are particularly suitable to the evaluation of these projects. Therefore this option gives the holder the possibility to abandon the project, if certain events, specially unfavourable, occur or damaging information arrives [16]. R\&D intensive industries, like pharmaceuticals, long-development capital-intensive projects and start-ups are examples of investments for which these types of options may be applied.

The option to change the operating scale (to expand, to contract, to shut down and to restart) provides the decision maker the poten-tial, for example to expand the scale of production or to accelerate resource utilization, if market conditions are promising. Otherwise, if the market conditions are unpromising, the operating scale can be reduced [11]. These options are important in all kind of produc-tion industries, natural-resource industries, facilities planning and construction, consumer goods and commercial real-estate firms.

In some situations, markets changes reveal to be adverse to the investment. It becomes then necessary to abandon it and, perhaps, realize the resale of capital equipment and other assets. This can be extremely important in order not to lose an entire investment and the option reasoning offers a away to evaluate this possibility [17]. Abandon options are important in capital-intensive industries such as airlines and railroads, financial services and introduction of new products in uncertain markets.

The option to switch allows the decision maker to evaluate the possibility to switch the inputs or the outputs of their business. This possibility will ensure a great adaptive flexibility to market changes. For example, if there are changes in prices or demand, the management can change the types of products produced (out-puts), giving product flexibility. On the other hand, the same types of products can be produced from different types of raw material (inputs), giving process flexibility $[11,18]$.

In some investment projects, the possibility to expand in the future may exist. The growth options can be interpreted like the acquisition of a capability that allows the firm to take better advan-tage of future growth opportunities, unlike companies that do not acquire the these options [19]. These options are important in all infrastructure based or strategic industries such as high tech and R\&D, industries with multiple product generation or application like pharmaceutical, multinational and strategic acquisitions.

\section{Valuing real options}

To introduce some valuing models it is important to select and describe the main variables that influence the value of real options. As mentioned earlier, an option has a value in a specified period of time. According to Copeland and Antikarov [14] this value depends, essentially on six variables. First, the value of the underlying asset, which in the case of real options is a project, investment or acquisition. If the value of the asset goes up, so does the value of the real option. Second, the exercise price. If the exercise price increases, the value of the option decreases. Third, the time to expiration of the option. If this time increases, so does the value of the option. Fourth, the uncertainty about the present value. In an environment with managerial flexibility an increase in uncertainty will increase the value of the real option. Fifth, the risk-free rate of interest over the life of the option. As the risk-free rate goes up, so does the value of the real option. The final variable is the dividends that may be paid out by the underlying asset. An increase of the dividends paid out will increase the value of the real option.

Having these variables identified, it is possible to start valuing real options. To do this, Amram and Kulatilaka [20], proposed a four step solution process. These four steps are guided by the financial markets in order: (i) to better frame the application of real options, (ii) to identify the inputs and the valuation models, (iii) to provide benchmark for interpreting results. The fourth step includes the application framing, the implementation of the option valuation model, the review of the results and the redesign if necessary.

The first step, application framing, requires a line of thought to be followed. In the first instance, realize what are the possi-ble decisions that could be taken and when might they be made. Chorn and Shokhor [21] developed policies for decision making in their work for petroleum development investments. Firstly, the authors start to understand the problem they had in hands and then demonstrated a policy development. They realize what are the deci-sions, when and how these decisions should be made. In the second instance, it is necessary to discover the sources of uncertainty and how they evolve. All the real options applications contain a study of the uncertainty. As an example of this, the work of Yang and Blyth [22] is used. Apart from identifying the sources of uncertainty and how they evolve, the authors had developed models for all kind of uncertainties. Identified the decision options and the uncertainties value, it is possible to create a mathematical expression, i.e., the decision rule. For example, in the case the decision is similar to a defer option, the decision rule could be: the option will not be exer-cised if the expected profits exceed the expected cost by a margin that exceeds the deferring value [23]. Next, it is necessary to look to the financial markets and then review this first step for simplic-ity. This final item concludes the first step of Amram and Kulatilaka [20] four step solution process.

The second step, implementation of the option valuation model, requires that the first step has been completed. Amram and Kulati-laka [20] presented, for this second step, only a brief survey of the solution methods available as described below. When trying to cal-culate option values there are several methods that use solution and mathematical techniques. However their implementation is guided by the Black, Merton and Scholes breakthrough [13,24].

Like in the first step, in the second step also a line of though should be followed. Hence, the first thing to do is to establish the mathematical representation. In other words, the representation of the stochastic processes: the payoff functions and the decision rules in mathematical terms. The second thing to do is to choose the solution method (or the option calculator). In fact, each solu-tion method has many ways to solve their mathematical models - they are called option calculators. Amram and Kulatilaka [20] orga-nize these solution methods in three groups: the partial differential equation (pde) approach, the dynamic programming approach and the simulation approach. The pde approach consists in expressing mathematically the value of an option and its dynamics by a partial differential equation and boundary conditions. This approach can be solved by analytical solutions, analytical approximations and numerical solutions. Cortazar et al. [25], in their work, presented 
a model that determine when it is optimum for a firm to invest in environmental technologies and which are the main parame-ters that affect the decision. They assumed that the price follow a geometric Brownian motion, used Itô calculus to compute the total differential of a function stochastic variable and the out-come of that analysis was a partial differential equation for the value of the real or financial option. The dynamic programming approach optimizes the decision that influences future payoffs, i.e., ". . . how to make optimal decisions when the current decision influ-ences future payoffs" [20]. This is a handy tool for option valuation because intermediate values and decisions become visible, provid-ing the user valuable information about the option and how to deal with complex decision structures. There are many ways to solve this approach, one of which is the binomial option valuation model. For an example of dynamic programming approach, Deng and Xia [26] proposed a stochastic dynamic programming valuation model for pricing electricity tolling agreements. The authors also tested their model and the effects of different electricity price assumptions on the valuation of tolling contracts resourcing to numerical examples. Simulation approaches roll out thousands of possible paths of evo-lution of the underlying asset from the present to the final decision date in the option [20]. In Monte Carlo simulation method, which is the method frequently used, the optimal investment strategy at the end of each path is determined and the payoff calculated. This method can handle many real life situations (for example, compli-cated decision rules and complex relationships between the option value and the underlying asset) and are computationally less ardu-ous. Examples of application are given in the work of Deng and Xia [26] and in the work of Yang and Blyth [22], both in the field of energy.

The third step of the Amram and Kulatilaka [20] approach is to review the results. It is important that authors' review the results obtained and compared them with other methods, such as dis-counted cash flow. The final step is the redesign. After reviewing the results, redesign the option valuation model to produce better results may be necessary. Besides the Amram and Kulatilaka [20] approach, other authors (e.g., Copeland and Antikarov [14] or Dixit and Pindyck [9]) presented real option valuation processes.

\section{Application of the real options theory to the energy sector}

The energy sector, since 1970, has suffered market, regulatory and technological changes. In this new context traditional capital budgeting methods are no longer sufficient to properly evaluate investments in this sector. In fact, this sector has moved from a regulated and monopolistic sector to a deregulated, uncertain and highly competitive sector [27].

This change opened the way to the application of the real options theory. To illustrate the increased importance of the real options approach on the energy sector, in the following paragraphs, an "historical" perspective is attempted and several examples are briefly described. The application of the real options theory to the renew-able energy investment projects will be described in more detail in the next subsection. The first applications of this theory remount to 1979, with the work of Tourinho [28]. Brennan and Schawrtz [29] applied option pricing methods to the evaluation of irreversible natural resources using the Chilean copper mines. At the same time, other authors developed work in the energy sector, more specifi-cally in the oil industry, like Siegel et al. [30], Paddock et al. [31] and Ekern [32].

In the decade of 1990-2000, Dixit and Pindyck [9], Trigeorgis [33] and Amram and Kulatilaka [20], contributed to the develop-ment of the real options approach application/use publishing books on this issue, giving an emphasis to examples and case applications, in several industries and or markets, including the energy sec-tor.

In 1996, Felder [34] argued that an increase in the use of finan-cial theory and methods would be expected, as electricity industry becomes more deregulated.

Ghosh and Ramesh [35] investigated the development of an options market for bulk power trading in a market setup while considering power systems planning and operational constraints and/or requirements. They proposed a solution to option pricing in electricity futures prices. They also noted that a massive change in the electric power supply industry was about to occur.

One year later, Hsu [36] wrote an article arguing that the owners of natural gas power plants should view their assets as a series of spark spread call options. The author also stated that ignoring this concept will inevitably lead to financial losses.

Frayer and Uludere [37] demonstrated how a real-options based valuation reveals and correctly quantifies the value of efficient plant operation in face of volatile electricity market prices. The authors used a pricing model that is a derivation of the spark-spread prin-ciple and adjusted the Black-Scholes formula for pricing options on real assets. The analysis showed that for the used example a peaking gas-fired facility may be more valuable than a coal-fired plant, contradicting the results achieved with the traditional DCF methods. Also, Deng et al. [38] presented a methodology to valuing electricity derivatives. They also developed a real options valuation for generation and transmission assets.

Armstrong et al. [39] presented a case study on oilfield produc-tion enhancement. The aim of their study was to evaluate the option to acquire more information. To do that, they incorporated in a real options model a Bayesian analysis. Through their example, they showed that Bayesian analysis coupled with real options provides a general framework for evaluating the option to obtain additional information. Moreira et al. [40], studied thermal power genera-tion investments for the case of Brazil. The authors resourced to a stochastic dynamic programming approach and to real options the-ory to develop a model to calculate the investment attractiveness for power generators to assess the regulatory effect on the invest-ment attractiveness, to evaluate the effect of the thermo generation share upon the system expansion cost and to assess the effect of thermo power operation flexibility on the system operating cost.

Hlouskova et al. [41] presented a model for the unit commit-ment problem base on real option theory. The authors implemented the real options model of Tseng and Barz [42] and applied it to value and optimally operate an electricity generation turbine in German market. At the same time, Madlener et al. [43] applied a dynamic technology adoption model for the evaluation of irre-versible investment options for electricity generation technologies. They took into account the uncertainty, the life-cycle capital and the operation costs. Their work contributed to the work of Mor-eira et al. [40], as the authors used a model accommodating plant availability, load duration curves, and irreversibility of investment similar to those of Moreira et al. [40].

One year later, Laurikka and Koljonen [44] studied the impacts of the European Union Emission allowance Trading Scheme (EU ETS) on investment decisions in Finland. They extended the traditional discounted cash flow analysis to take into account the value of two real options. Their study showed that the uncertainty regarding the allocation of emission allowances is critical in a quantitative investment appraisal of fossil fuel-fired power plants. Blyth and Yang [23] also focused in this issue and developed a work for Inter-national Energy Agency (IEA), to quantify the impacts of climate change policy on power investments. They used real options the-ory and modelled prices uncertainty with stochastic variables. In the same year, van Benthem et al. [45] developed a model, using options theory, to calculate the value and timing strategy of invest-ment in a hydrogen infrastructure as a transport fuel. Chorn and 
Shokhor [21] presented a work that extends the applicability of real options theory from a valuation technique to a policy guid-ance tool. That was the first demonstration of a mathematical union between two techniques of decision, real options and the Belman equation, providing a generalized policy framework that gives risk management of investments. Nevertheless to date there was no quantitative demonstration of the proposed framework. Deng and Xia [26] proposed a real options model to value a tolling contract. They used dynamic programming and valuated function approx-imation by Monte Carlo simulation. Also in 2006, Marreco and Carpio [12] presented a valuation study of operational flexibility in the complex Brazilian Power System. They applied the real options theory in order to create a methodology that could compute the fair values to be paid to a thermal power generator merely for its availability to the system.

In 2007, Botterud and Korpas [46] studied the effect of power system restructuring on investments in new generation capacity and developed an optimization model for optimal timing. They used real options theory to deal with the question of how uncertainties in future demand influence prices in the electricity market. Their model can be used to analyse the interrelated dynamics of elec-tricity spot and capacity price, and its effect on profitability and optimal investment timing.

One year later, Prelipcean and Boscoianu [47] presented an integrated framework to evaluate decisions in energy investments. Their framework incorporated real options theory and artificial neural networks.

In 2009, Abadie [48] conducted a study which aimed to con-tribute to the development of valuation models for long-term investments in energy assets, using real options theory. Bonis et al.

[49] studied a real investment case related to the expansion of Endesa in Latin American, applying real options theory. Fuss et al.

[50] presented a real options model to evaluate the impact of cli-mate change policy to the energy sector. Uc, al and Kahraman [51] proposed a new fuzzy real options valuation model to evaluate oil investments.

In 2010, several works applying real options to the energy sector were presented. Fan and Zhu [52] developed a real options model to help in the decision-making process on overseas oil investment decisions. Fleten and Näsäkkälä [53] presented a case study of gasfired plants using real options analysis, in Scandinavia. They also provided upper and lower bounds for investment thresholds and plant values that depend on the degree of operating flexibility of the plant.

This description thus not intends to be exhaustive but rather demonstrates the diversity of methods and problems approached under the real options theory. Table 2 summarizes the historical perspective of the studies reviewed in this section, applying real options theory to support decision making on the energy industry, companies and markets.

\subsection{Application of the real options theory to renewable energy sources investment projects}

In this section the presentation of the applications of the real options theory to renewable energy will be addressed, focusing on three major areas: power generation, policy evaluation and $R \& D$ investments/programs.

\subsubsection{Real options theory in power generation investment}

To the authors' best knowledge, one of the first applications of the real options theory to the renewable energy field, wind energy exploitation more precisely, dates back to 2002 , by Venetsanos et al. [54]. The authors identified a framework to evaluate renewable energy power projects. Firstly, they considered the uncertainties and the directly related resource attributes, which are inherent to the energy production. Secondly, they identified the real options embedded to a wind energy project. Thirdly, they evaluated the project, according the real options theory. For that they used the BlackScholes Model. Finally, they compared the results of their model with the traditional Discounted Cash Flow technique. The major findings of their work were that the option value was posi-tive, while the net present value was negative. It was only on 2007, in Norway, that Kjarland [55] applied real options theory to assess the value of hydropower investment opportunities, and to find the relation between price level of electricity and optimal timing of investment decisions in hydropower sector. They used the frame-work developed by Dixit and Pindyck [9]. Following the same line of research, Bockman et al. [56] presented a real options based method for assessing small hydropower projects. They applied their method to three different Norwegian hydropower projects. In 2009, Munoz et al. [3] developed a model to evaluate wind energy invest-ments. The authors used a stochastic model for the parameters affecting the NPV and a real options model to evaluate the prob-abilities to invest, wait or abandon the project. They also applied their model to several case studies. Martínez-Cesena and Mutale [4] showed that projects planned with real options methodology show higher expected profits than projects using other methods. They also developed an advanced real options methodology for renew-able energy generation projects, illustrating their methodology in a hydropower case study.

\subsubsection{Real options theory in policy evaluation}

One of the first applications of the real options theory to this area dates back to 2006, by $\mathrm{Yu}$ et al. [57]. They used real options techniques to evaluate switching tariff for different wind genera-tion assets, and to identify optimal switching policies and values, in Spanish electricity markets. Two years later, in 2008, Kum-baroglu et al. [5] presented a policy planning model that integrates learning curve information on renewable power generation tech-nologies into a dynamic programming formulation containing real options theory. Note that the model was successfully applied in Turkey. One year later, Siddiqui and Fleten [58] examined how a staged commercialization programme for an unconventional energy technology could proceed under uncertainty. Lee and Shih [59] presented a policy benefit evaluation model using real option pricing techniques and considered uncertainty and others fac-tors that impact policy for developing renewable energy. Their framework allows to assess volatility, uncertainty, and managerial flexibility in policy planning.

\subsubsection{Real options theory in R\&D investments/programs}

One of the first applications of the real options theory to this area dates back to 2003 , by Davis and Owens [60]. They quanti-fied the value of the United States federal non-hydro renewable electric $R \& D$ program based on a real options model. They also use that model to determine the optimal level of annual federal renew-able energy R\&D expenditures. In 2007, Siddiqui et al. [61] assessed the strategy for renewable energy $R \& D$ in the United States. They studied the deterministic approach employed by the Department of Energy and the real options model developed by Davis and Owens [60]. For that purpose, they developed a real options model, but on the contrary of Davis and Owens' model, they used a binomial lattice structure. They argued that a binomial lattice reveals the economic intuition underlying the decision-making process, while a numerical example illustrates the option components embed-ded in a simplified representation of current US Federal renewable energy research, development, demonstration and deployment. Their model has been implemented in MATLAB ${ }^{\circledR}$.

Table 3 summarizes all the studies that applied real options theory to RES that are referred in this section. 
Table 2

Historical perspective of the reviewed studies applying real options theory.

\begin{tabular}{|c|c|c|c|c|}
\hline Authors & Year & Application & Solution method & Ref. \\
\hline Siegel et al. & 1987 & Oil industry & Pde & {$[30]$} \\
\hline Paddock et al. & 1988 & Oil industry & Pde & [31] \\
\hline Ekern & 1988 & Oil industry & Binomial option valuation & [32] \\
\hline Dixit and Pindyck & 1994 & Book: case studies in energy sector & & [9] \\
\hline Trigeorgis & 1996 & Book: case studies in energy sector & & [33] \\
\hline Amram and Kulatilaka & 1999 & Book: case studies in energy sector & & {$[20]$} \\
\hline Felder & 1995 & Power generation & Binomial option valuation & [34] \\
\hline Ghosh and Ramesh & 1997 & Energy market & Pde & [35] \\
\hline Hsu & 1998 & Power generation & Pde & {$[36]$} \\
\hline Frayer and Uludere & 2001 & Power generation & Pde & [37] \\
\hline Deng et al. & 2001 & Energy market & Pde & {$[38]$} \\
\hline Armstrong et al. & 2004 & Oil industry & Pde; Monte Carlo simulation & [39] \\
\hline Moreira et al. & 2004 & Power generation & Dynamic programming & {$[40]$} \\
\hline Hlouskova & 2005 & Power generation & Monte Carlo Simulation & {$[41]$} \\
\hline Madlener et al. & 2005 & Power generation & Dynamic programming & {$[43]$} \\
\hline Laurikka and Koljonen & 2006 & Impact of emission policy & Pde; Monte Carlo simulation & {$[44]$} \\
\hline van Benthem et al. & 2006 & Power generation & Dynamic programming & [45] \\
\hline Chorn and Shokhor & 2006 & Policies study & Dynamic programming & [21] \\
\hline Blyth and Yang & 2006 & Impact of climate change policy & Monte Carlo simulation; dynamic programming & [23] \\
\hline Deng and Xia & 2006 & Energy market & Dynamic programming; Monte Carlo simulation & {$[26]$} \\
\hline Marreco and Carpio & 2006 & Power generation & Pde & {$[12]$} \\
\hline Botterud and Korpas & 2007 & Energy market & Dynamic programming & {$[46]$} \\
\hline Prelipcean and Boscoianu & 2008 & Energy market & Dynamic programming & {$[47]$} \\
\hline Abadie & 2009 & Energy market & Pde & {$[48]$} \\
\hline Bonis et al. & 2009 & Energy market & Pde & [49] \\
\hline Fuss et al. & 2009 & Impact of climate change policy & Pde; Monte Carlo simulation & {$[50]$} \\
\hline Uc, al and Kahraman & 2009 & Oil industry & Pde & {$[51]$} \\
\hline Fan and Zhu & 2010 & Oil industry & Pde & {$[52]$} \\
\hline Fleten and Näsäkkälä & 2010 & Power generation & Pde & [53] \\
\hline
\end{tabular}

Table 3

Historical perspective of the reviewed studies applying real options theory to renewables.

\begin{tabular}{|c|c|c|c|c|c|}
\hline Authors & Year & Resource type & Area of application & Solution Method & Ref \\
\hline Venetsanos et al. & 2002 & Wind energy & Power generation & Pde & [54] \\
\hline Davis and Owens & 2003 & Renewable energy technologies & R\&D program & Pde & {$[60]$} \\
\hline Yu et al. & 2006 & Wind energy & Policy evaluation & Pde & [57] \\
\hline Kjarland & 2007 & Hydropower & Policy evaluation & Pde & {$[55]$} \\
\hline Siddiqui & 2007 & Renewable energy & $R \& D$ investments & Pde; dynamic programming & [61] \\
\hline Bockman et al. & 2008 & Hydropower & Power generation & Pde; dynamic programming & [56] \\
\hline Kumbarogluॅ et al. & 2008 & Renewable energy technologies & Policy evaluation & Dynamic programming & [5] \\
\hline Munoz et al. & 2009 & Wind Energy & Power generation & Dynamic programming & [3] \\
\hline Siddiqui and Fleten & 2010 & Renewable energy technologies & Policy evaluation & Pde; dynamic programming & [58] \\
\hline Lee and Shih & 2010 & Renewable energy & Policy evaluation & Pde; dynamic programming & [59] \\
\hline Martínez-Cesena and Mutale & 2011 & Hydropower & Power generation & Dynamic Programming; Monte Carlo Simulation & [4] \\
\hline
\end{tabular}

\section{Conclusion}

An increase on the interest and application of the real options theory to the energy sector decision making has been noticed dur-ing the last years. As seen in the presented literature review, this theory has been used to all sectors in the energy, from generation to evaluation of policies. This increase reveals that the interested parties in the energy sector now understand the limitations of the traditional techniques, given the potential of the real options the-ory. The RES sector is no exception and a few studies using the real options theory appeared recently in the literature, although this particular literature is still limited.

RES projects have particular characteristics that imply selecting methods capable to assess their correct value taking into account these particularities. Namely, these projects have high initial costs, high financial risk and uncertainties. These uncertainties are caused by their natural sources variability, the possible changes in the support schemes and by their learning curves exhibiting very steep slopes. These projects interest is also indirectly affected by the prices of the fossil fuel price and consequently by the prices of the electricity and, as so, the markets uncertainty also affects these kinds of projects. Taking into account the exposed reasons, real options theory seems to be an evaluation method that can provide a more realistic value of a RES investment project. However, there seems to exist a lack of application of this technique to this field and, as so, the authors frequently resource to the simulation of the application. Real options proved that can produce better results than other methods. To the author's best knowledge this tech-nique was not frequently applied to other RES, beyond wind power and hydropower. Therefore, the development of real options and further application methodologies to other RES, like photovoltaics and or biomass, and others, can provide better knowledge of their correct value.

From the moment that the energy sector started a deregula-tion process, with a high level of competitiveness and associated increased in market uncertainty, traditional project evaluation techniques alone became insufficient to properly deal with these additional risk and uncertainty factors. The diffusion of the RES technologies is also affected by this feature, so, the way investors evaluate their investments call for the use of more sophisticated evaluation techniques. Real options theory, gives the investor the ability to account for the value inherent in the flexibility to delay an irreversible investment into the future. In the RES projects field, this ability become particularly important, as these are often modu-lar, normally require short construction times and exhibit learning curves with very steep slopes. 


\section{Acknowledgments}

This work was financed by: the QREN - Operational Programme for Competitiveness Factors, the European Union - European Regional Development Fund and National Funds- Portuguese Foundation for Science and Technology, under Project FCOMP-010124-FEDER-011377 and Project Pest-OE/EME/UI0252/2011.

\section{References}

[1] Menegaki A. Valuation for renewable energy: a comparative review. Renewable and Sustainable Energy Reviews 2008:12:2422-37.

[2] Haas R, Panzer C, Resch G, Ragwitz M, Reece G, Held A. A historical review of promotion strategies for electricity from renewable energy sources in EU countries. Renewable and Sustainable Energy Reviews 2011;15:1003-34.

[3] Munoz JI, Contreras J, Caamano J, Correia PF. Risk assessment of wind power generation project investments based on real options. In: IEEE Bucharest power tech. conference. 2009

[4] Martínez-Cesena ${ }^{\sim}$ EA, Mutale J. Application of an advanced real options approach for renewable energy generation projects planning. Renewable and Sustainable Energy Reviews 2011;15:2087-94.

[5] Kumbaroglu G, Madlener R, Demirel M. A real options evaluation model for the diffusion prospects of new renewable power generation technologies. Energy Economics 2008;30:1882-908.

[6] Bennouna K, Meredith GG, Marchant T. Improved capital budgeting decision making: evidence from Canada. Management Decision 2010;48:225-47.

[7] Graham JR, Harvey CR. How do CFOs make capital budgeting and capital structure decisions? The Journal of Applied Corporate Finance 2002;15:187-243.

[8] Ryan PA, Ryan GP. Capital budgeting practices of the fortune 1000: how have things changed? Journal of Business and Management 2002;8:389-419.

[9] Dixit AK, Pindyck RS. Investment under uncertainty. New Jersey: Princeton University Press; 1994.

[10] Myers SC. Determinants of corporate borrowing. Journal of Financial Economics 1977; (November):147-75.

[11] Trigeorgis L. Real options: a primer. In: Alleman J, Noam E, editors. The new investment theory of real options and its implication for telecommunications economics. Springer US; 2000. p. 3-33.

[12] Marreco JM, Carpio LGT. Flexibility valuation in the Brazilian power system: a real options approach. Energy Policy 2006;34:3749-56.

[13] Black F, Scholes M. The pricing of options and corporate liabilities. The Journal of Political Economy 1973;81:637-54.

[14] Copeland T, Antikarov V. Real options: A practitioner's guide. New York: Cengage Learning; 2003.

[15] Kogut B, Kulatilaka N. Capabilities as real options. Organization Science 2001;12:744-58

[16] Majd S, Pindyck RS. Time to build, option value, and investment decisions. Journal of Financial Economics 1987;18:7-27.

[17] Myers SC, Majd. S. Abandonment value and project life. Advances in Futures and Options Research 1990;4:1-21.

[18] Kulatilaka N, Trigeorgis L. The general flexibility to switch: real options revis-ited. International Journal of Finance 1994;6.

[19] Kulatilaka N, Perotti EC. Strategic growth options. Management Science 1998;44:1021-31.

[20] Amram M, Kulatilaka N. Real options: managing strategic investment in an uncertain world. Harvard Business School Press; 1999.

[21] Chorn L, Shokhor S. Real options for risk management in petroleum development investments. Energy Economics 2006;28:489-505.

[22] Yang M, Blyth W. Modeling investment risks and uncertainties with real options approach. IEA working paper; 2007.

[23] Blyth W, Yang M. Impact of climate change policy uncertainty in power investment. IEA working paper; 2006.

[24] Merton RC. Theory of rational option pricing. The Bell Journal of Economics and Management Science 1973;4:141-83.

[25] Cortazar G, Schwartz ES, Salinas M. Evaluating environmental investments: a real options approach. Management Science 1998:44:1059-70.

[26] Deng S-J, Xia Z. A real options approach for pricing electricity tolling agreements. International Journal of Information Technology \& Decision Making 2006;5:421-36.

[27] Awerbuch S, Dillard J, Mouck T, Preston A. Capital budgeting, technological innovation and the emerging competitive environment of the electric power industry. Energy Policy 1996;24:195-202.

[28] Tourinho OAF. The valuation of reserves of natural resources: an option pricing aproach. Berkeley: University of California; 1979.

[29] Brennan MJ, Schwartz ES. Evaluating natural resource investments. The Journal of Business 1985;58:135-57.
[30] Siegel DR, Smith JL, Paddock JL. Valuing offshore oil properties with option pricing models. Midland Corporate Finance Journal 1987:22-30.

[31] Paddock JL, Siegel DR, Smith JL. Option valuation of claims on real assets: the case of offshore petroleum leases. The Quarterly Journal of Economics 1988;103:479-508.

[32] Ekern S. An option pricing approach to evaluating petroleum projects. Energy Economics 1988;10:91-9.

[33] Trigeorgis L. Real options: managerial flexibility and strategy in resource allocation. Cambridge, MA: MIT Press; 1996.

[34] Felder FA. Integrating financial theory and methods in electricity resource planning. Energy Policy 1996;24:149-54.

[35] Ghosh K, Ramesh VC. An options model for electric power markets. Interna-tional Journal of Electrical Power \& Energy Systems 1997;19:75-85.

[36] Hsu M. Spark spread options are hot! The Electricity Journal 1998;11: 28-39.

[37] Frayer J, Uludere NZ. What is it worth? application of real options theory to the valuation of generation assets. The Electricity Journal 2001;14:40-51.

[38] Deng S, Johnson B, Sogomonian A. Exotic electricity options and the valuation of electricity generation and transmission assets. Decision Support Systems 2001;30:383-92.

[39] Armstrong M, Galli A, Bailey W, Couët B. Incorporating technical uncertainty in real option valuation of oil projects. Journal of Petroleum Science and Engineering 2004;44:67-82.

[40] Moreira A, Rocha K, David P. Thermopower generation investment in Brazil economic conditions. Energy Policy 2004;32:91-100.

[41] Hlouskova J, Kossmeier S, Obersteiner M, Schnabl A. Real options and the value of generation capacity in the German electricity market. Review of Financial Economics 2005;14:297-310.

[42] Tseng C, Barz G. Short-term generation asset valuation: a real options approach. Operations Research 2002;50:297-310.

[43] Madlener R, Kumbaroglu` G, Ediger VS, . Modeling technology adoption as an irreversible investment under uncertainty: the case of the Turkish electricity supply industry. Energy Economics 2005;27:139-63.

[44] Laurikka $\mathrm{H}$, Koljonen T. Emissions trading and investment decisions in the power sector - a case study in Finland. Energy Policy 2006;34:1063-74.

[45] van Benthem AA, Kramer GJ, Ramer R. An options approach to investment in a hydrogen infrastructure. Energy Policy 2006;34:2949-63.

[46] Botterud A, Korpas M. A stochastic dynamic model for optimal timing of investments in new generation capacity in restructured power systems. International Journal of Electrical Power \& Energy Systems 2007;29:163-74.

[47] Prelipcean G, Boscoianu M. Computational framework for assessing decisions in energy investments based on a mix between Real Option Analysis (ROA) and artificial neural networks (ANN). In: 9th WSEAS international confer-ence on mathematics \& computers in business and economics (MCBE '08). 2008.

[48] Abadie LM. Valuation of long-term investments in energy assets under uncertainty. Energies 2009;2:738-68.

[49] Bonis SA, Palenzuela VA, Herrero GdlF. Las opciones reales en el sector eléctrico. El caso de la expansión de Endesa en Latinoamérica. Cuadernos de Economía y Dirección de la Empresa; 2009. Núm. 38:065-94.

[50] Fuss S, Johansson D, Szolgayova J, Obersteiner M. Impact of climate policy uncertainty on the adoption of electricity generating technologies. Energy Pol-icy 2009;37:733-43.

[51] Uc, al I, Kahraman C. Fuzzy real options valuation for oil investments. Technological and Economic Development 2009;15:646-69.

[52] Fan Y, Zhu L. A real options based model and its application to China's overseas oil investment decisions. Energy Economics 2010;32:627-37.

[53] Fleten S-E, Näsäkkälä E. Gas-fired power plants: investment timing, operating flexibility and $\mathrm{CO}_{2}$ capture. Energy Economics 2010;32:805-16.

[54] Venetsanos K, Angelopoulou P, Tsoutsos T. Renewable energy sources project appraisal under uncertainty, the case of wind energy exploitation within a changing energy market environment. Energy Policy 2002;30:293-307.

[55] Kjarland F. A real option analysis of investments in hydropower - the case of Norway. Energy Policy 2007:35:5901-8.

[56] Bockman T, Fleten S, Juliussen E, Langhammer H, Revdal I. Investment timing and optimal capacity choice for small hydropower projects. European Journal of Operational Research 2008;190:255-67.

[57] Yu W, Sheble G, Lopes J, Matos M. Valuation of switchable tariff for wind energy. Electric Power Systems Research 2006;76:382-8.

[58] Siddiqui A, Fleten S-E. How to proceed with competing alternative energy technologies: a real options analysis. Energy Economics 2010;32:817-30.

[59] Lee S-C, Shih L-H. Renewable energy policy evaluation using real option model the case of Taiwan. Energy Economics 2010;32:S67-78.

[60] Davis G, Owens B. Optimizing the level of renewable electric R\&D expenditures using real options analysis. Energy Policy 2003;31:1589-608.

[61] Siddiqui AS, Marnay C, Wiser RH. Real options valuation of US federal renewable energy research, development, demonstration, and deployment. Energy Policy 2007;35:265-79. 